Claves. Revista de Historia, Vol. $3, \mathrm{~N}^{\circ} 4$

Montevideo, Enero-Junio 2017

(pp. 245-250) ISSN 2393-6584

\title{
Primer Congreso de la Asociación Uruguaya de Historiadores (AUDHI)
}

Nicolás Duffau

Universidad de la República, Uruguay

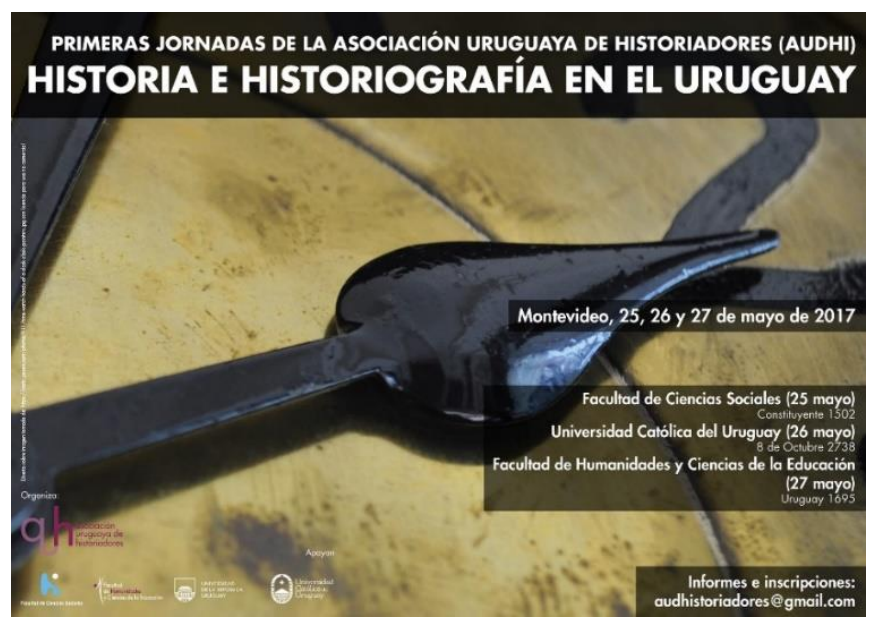

Entre el 25 y el 27 de mayo tuvo lugar el Primer Congreso de la Asociación Uruguaya de Historiadores (AUDHI), titulado Historia e historiografía en el Uruguay. El evento se desarrolló en tres sedes: Facultad de Ciencias Sociales y Facultad de Humanidades y Ciencias de la Educación de la Universidad de la República y Universidad Católica del Uruguay.

AUDHI es una organización fundada en 2015 por historiadores procedentes de diferentes ámbitos institucionales y busca contribuir a la promoción del papel profesional del historiador, difundir la investigación en Historia en toda su diversidad de enfoques y temas de estudio, fortalecer la enseñanza de la Historia en todos sus niveles, así como estimular el interés público respecto a la conservación del patrimonio y a la organización de bibliotecas, archivos y museos.

En el encuentro, inaugurado por Gerardo Caetano, presidente de AUDHI, participaron investigadores procedentes de distintas instituciones públicas y privadas del Uruguay lo que favoreció el intercambio entre estudiantes de maestría, doctorado e investigadores, así como un verdadero espacio 
interdisciplinario en el que convivieron la Historia Política con la Historia de la Arquitectura o de la Medicina, enfoques más vinculados a abordajes de tipo social con otros con una marcada impronta cultural, abordajes micros y perspectivas que apuntaron a la explicación de contextos o procesos más amplios. Asimismo fue un espacio para realizar un balance sobre los alcances y las limitaciones del método de trabajo del historiador y las características de los archivos en Uruguay. En este primer encuentro también realizó una exposición en calidad de invitado el reconocido historiador argentino Raúl Fradkin (Universidad de Buenos Aires y Universidad Nacional de Luján).

En total se presentaron cuarenta comunicaciones, divididas en cuatro mesas temáticas y seis paneles. Los paneles fueron sobre "Participación política", "Cultura, artes y medios", "Sujetos, grupos y movimientos sociales", "Futuro, utopía y desarrollo", "Historia rural, tierra y paisaje" y "Violencia política en la historia uruguaya", en los cuales se presentaron exposiciones que repasaron los puntos historiográficos y metodológicos más sobresalientes sobre los seis campos en cuestión. En los paneles la tónica sobresaliente fue la presencia de historiadores de distintas generaciones y provenientes de áreas temáticas variadas.

En las cuatro mesas las exposiciones mostraron diversos grados de avance, por tratarse de investigaciones en el marco de tesis de maestría, doctorado o elaborados en contextos de equipos de trabajo más amplios. Como en el caso de los paneles resultó favorable para el intercambio de perspectivas y enfoques que no siempre coinciden en los congresos de carácter temático.

Por último queda señalar la importante concurrencia de público y la presencia de estudiantes de grado de varias carreras, de formación docente (de Montevideo, Colonia, Salto y otras partes del país), docentes de enseñanza media, terciara y universitaria, por lo que también se cumplió con el objetivo primordial de promover el debate, transmitir el conocimiento generado en los últimos años y demostrar la vigencia de los estudios históricos en nuestro país. El primer congreso de AUDHI abre un panorama auspicioso para el desarrollo de la investigación histórica y, más importante aún, da cuenta de la fortaleza y vigencia del campo de trabajo. 
Facebook de AUDHI: https://www.facebook.com/Audhi-Asociaci\%C3\%B3nUruguaya-de-Historiadores-1514006675569940/?ref=br rs

Twitter de AUDHI: https://twitter.com/Audhistoria

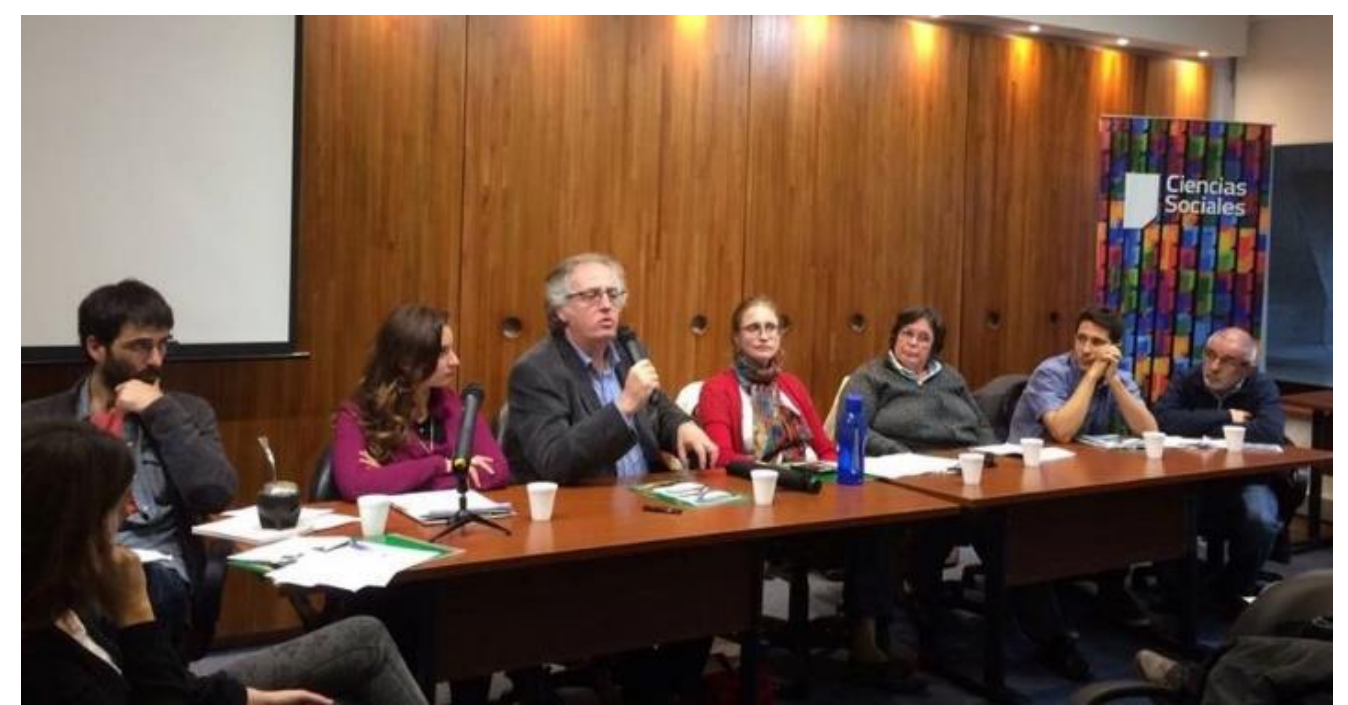

Mesa sobre Historia Política. (Facultad de Ciencias Sociales-FCS-UdelaR, 25/05/2017).

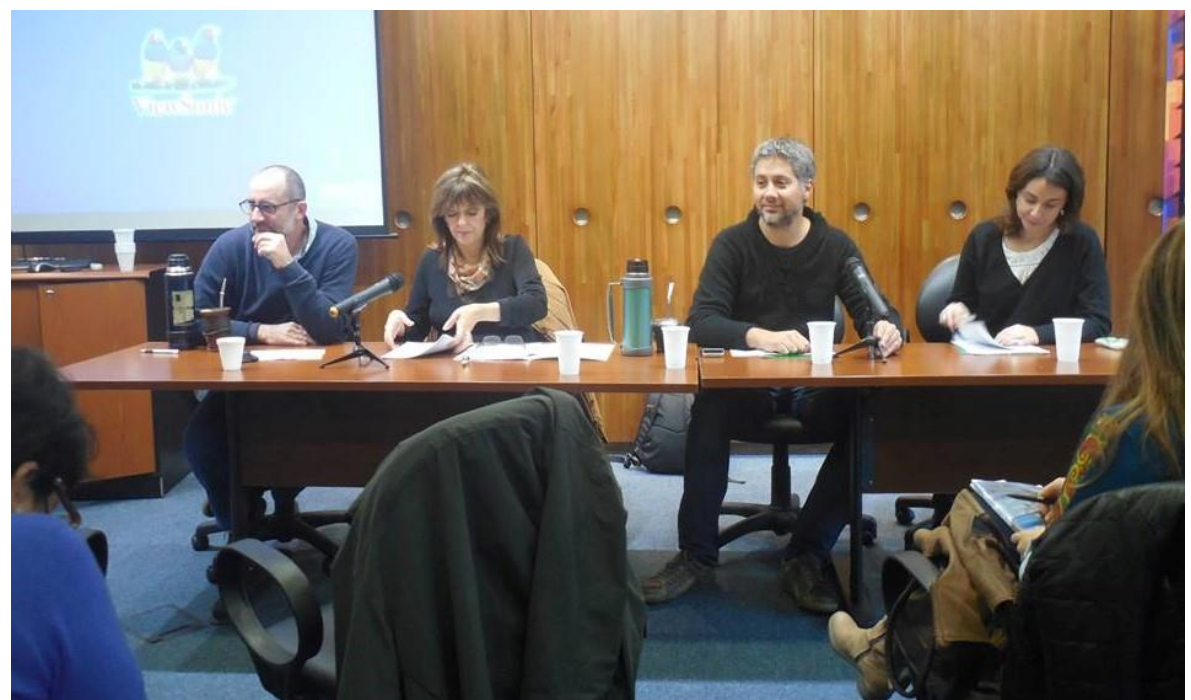

Panel sobre Participación política. (FCS, 25/05/2017) 


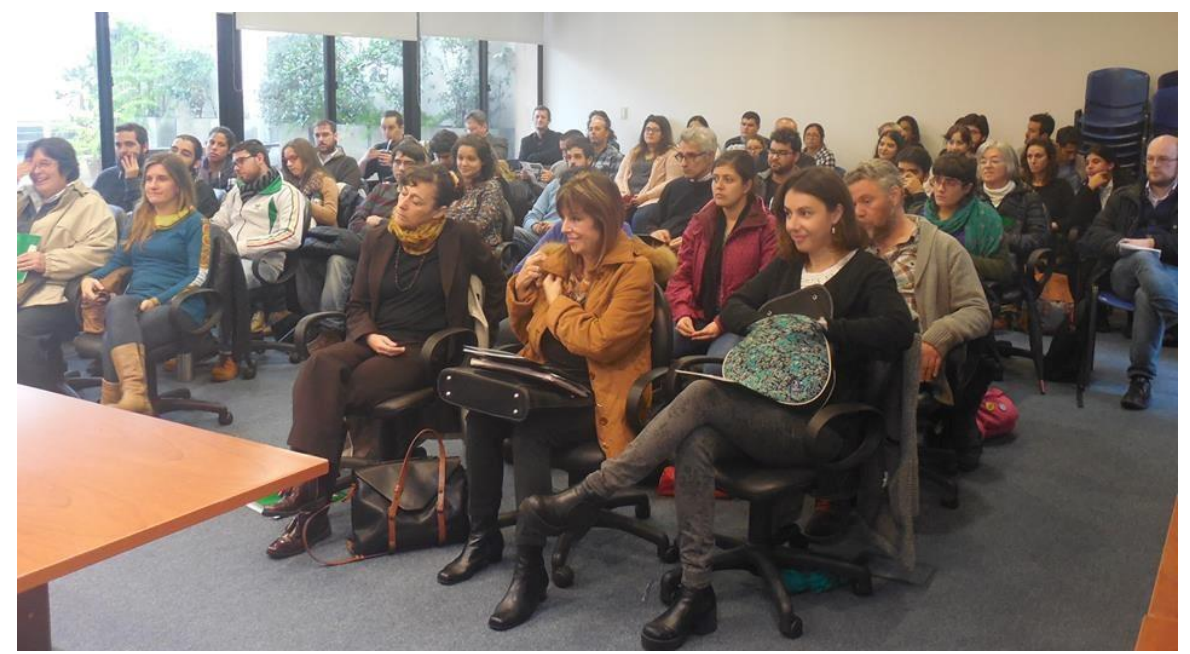

Asistentes a la primera jornada del congreso. (25/05/2017, FCS)

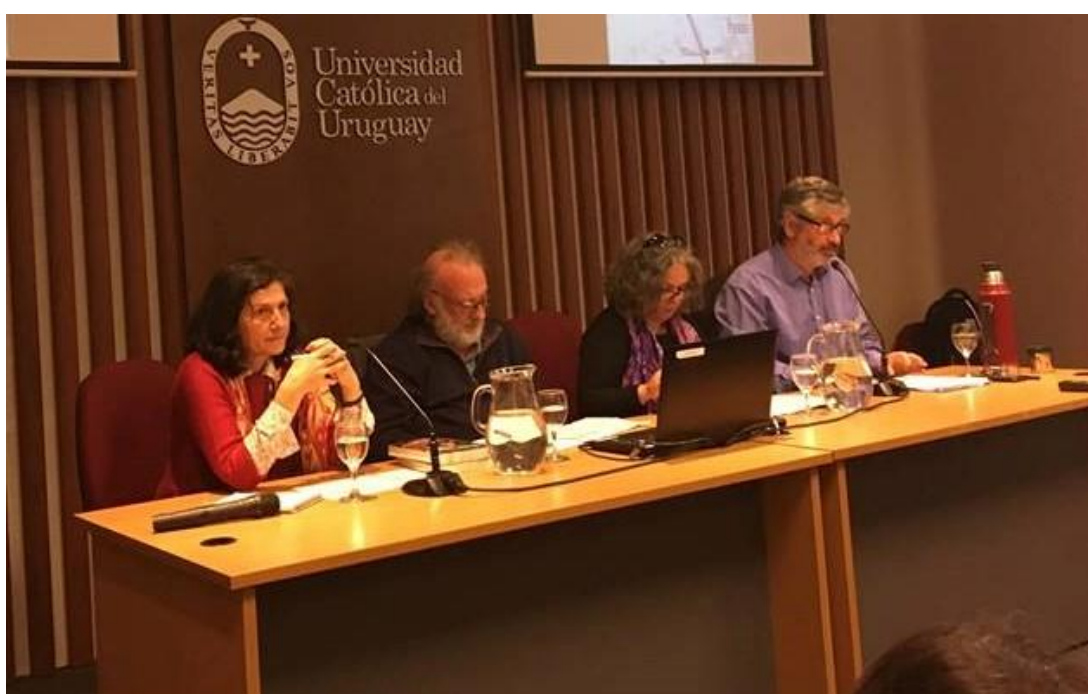

Panel sobre Sujetos, Grupos y movimientos sociales. (26/05/2017, Universidad Católica del Uruguay, UCU)

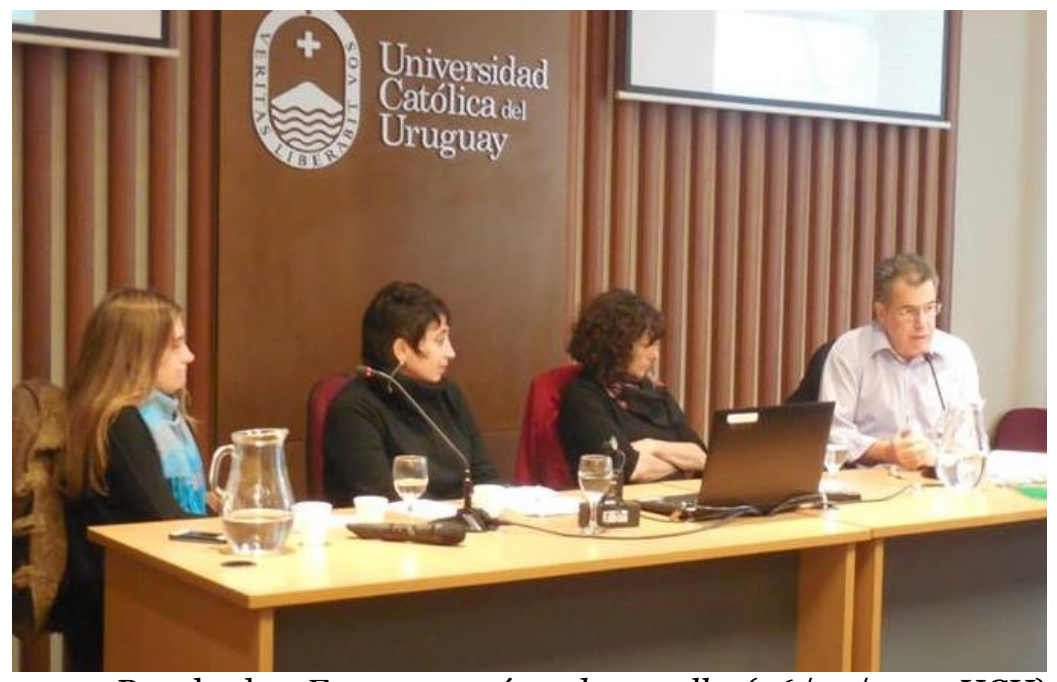

Panel sobre Futuro, utopía y desarrollo. (26/05/2017, UCU) 


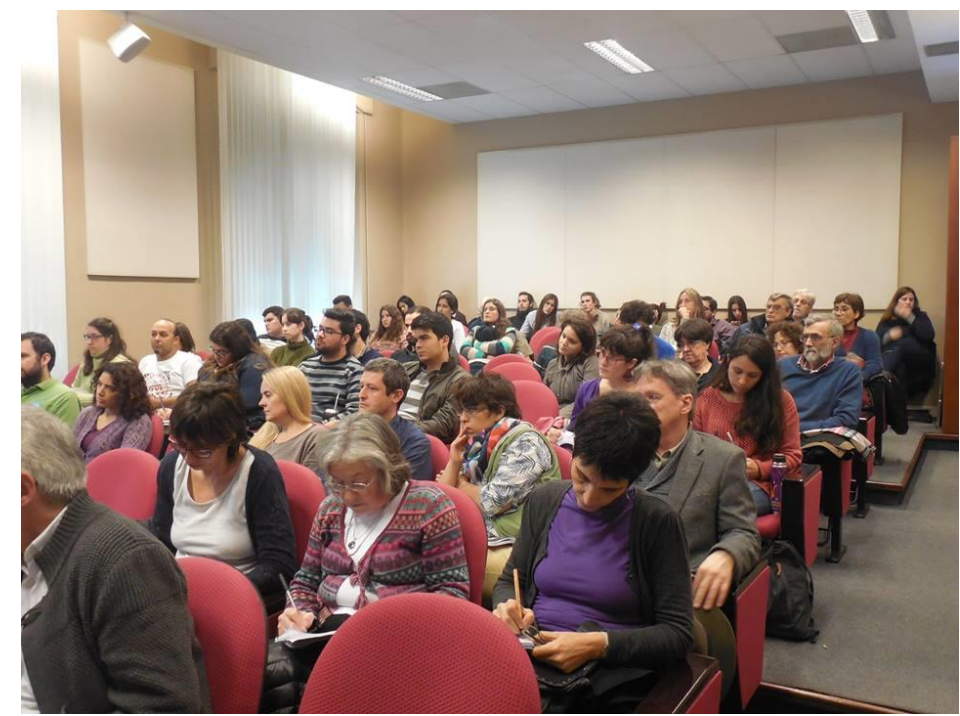

Participantes en uno de los paneles realizados en la Universidad Católica. (26/05/2017)

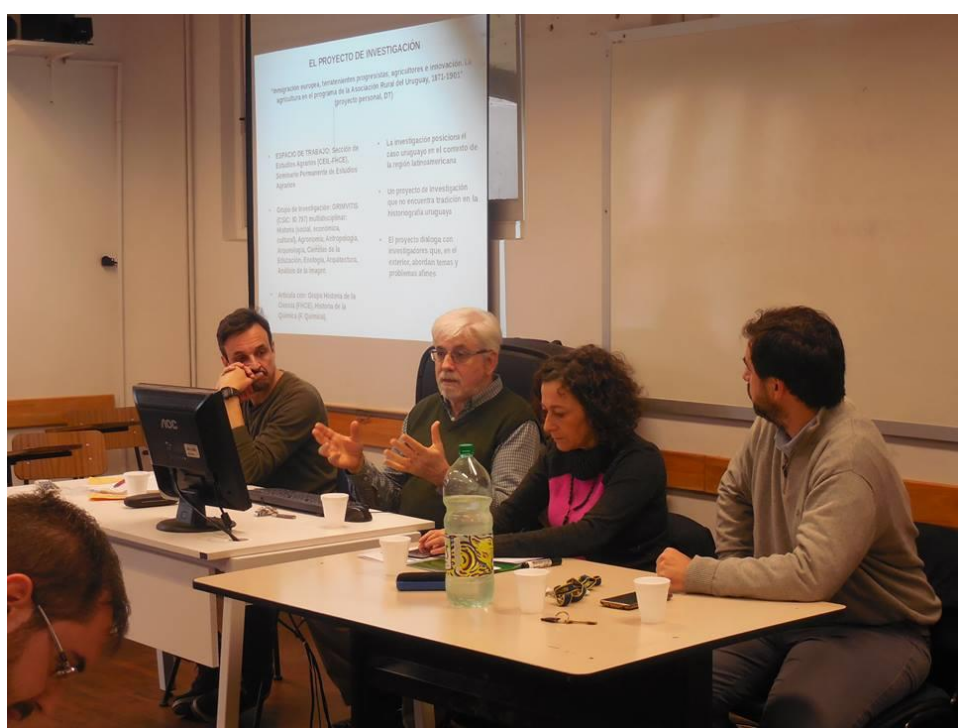

Panel sobre Historia Rural, tierra y paisaje. Facultad de Humanidades y Ciencias de la Educación (FHCE). (27/05/2017)

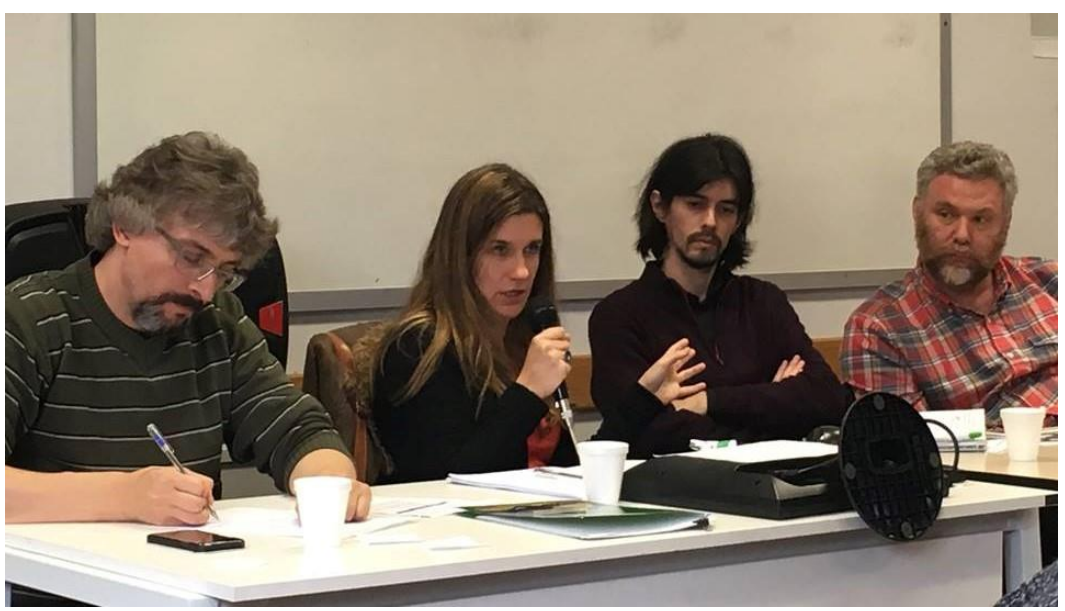

Panel sobre Violencia y política en la historia uruguaya. (FHCE, 27/05/2017) 


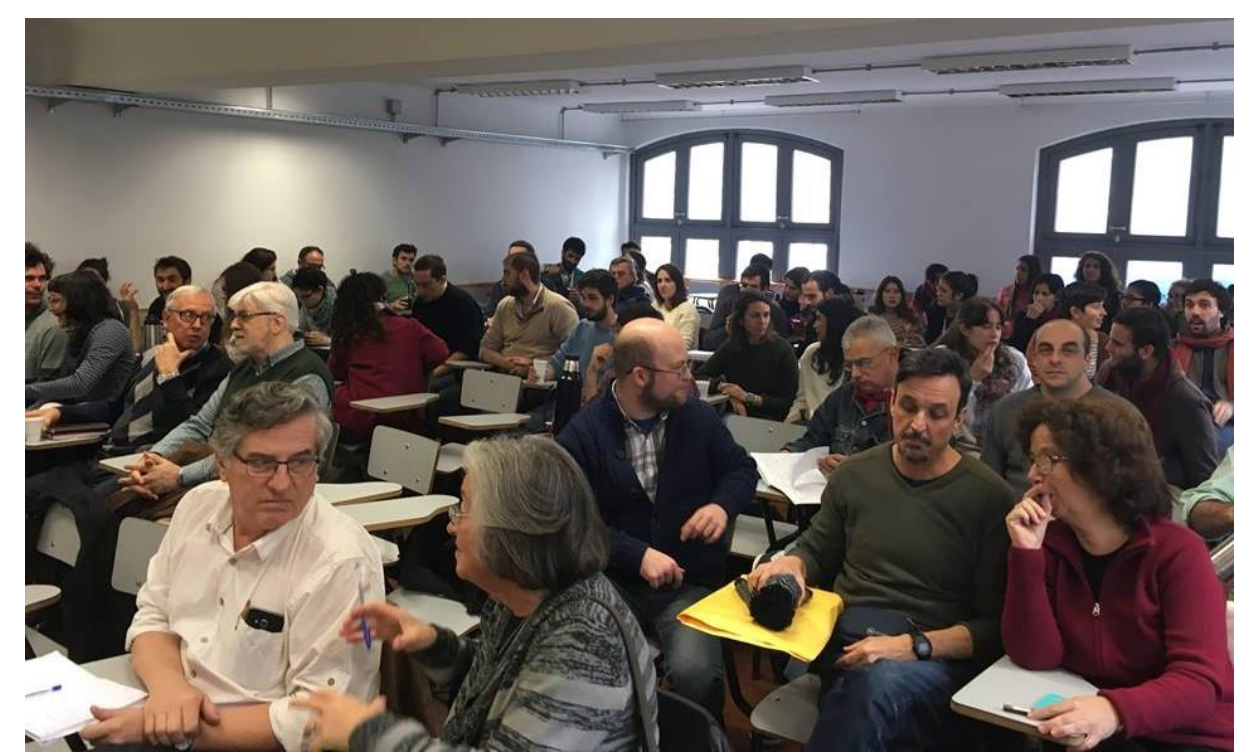

Asistentes a la jornada de cierre del congreso. (FHCE, 27/05/2017) 